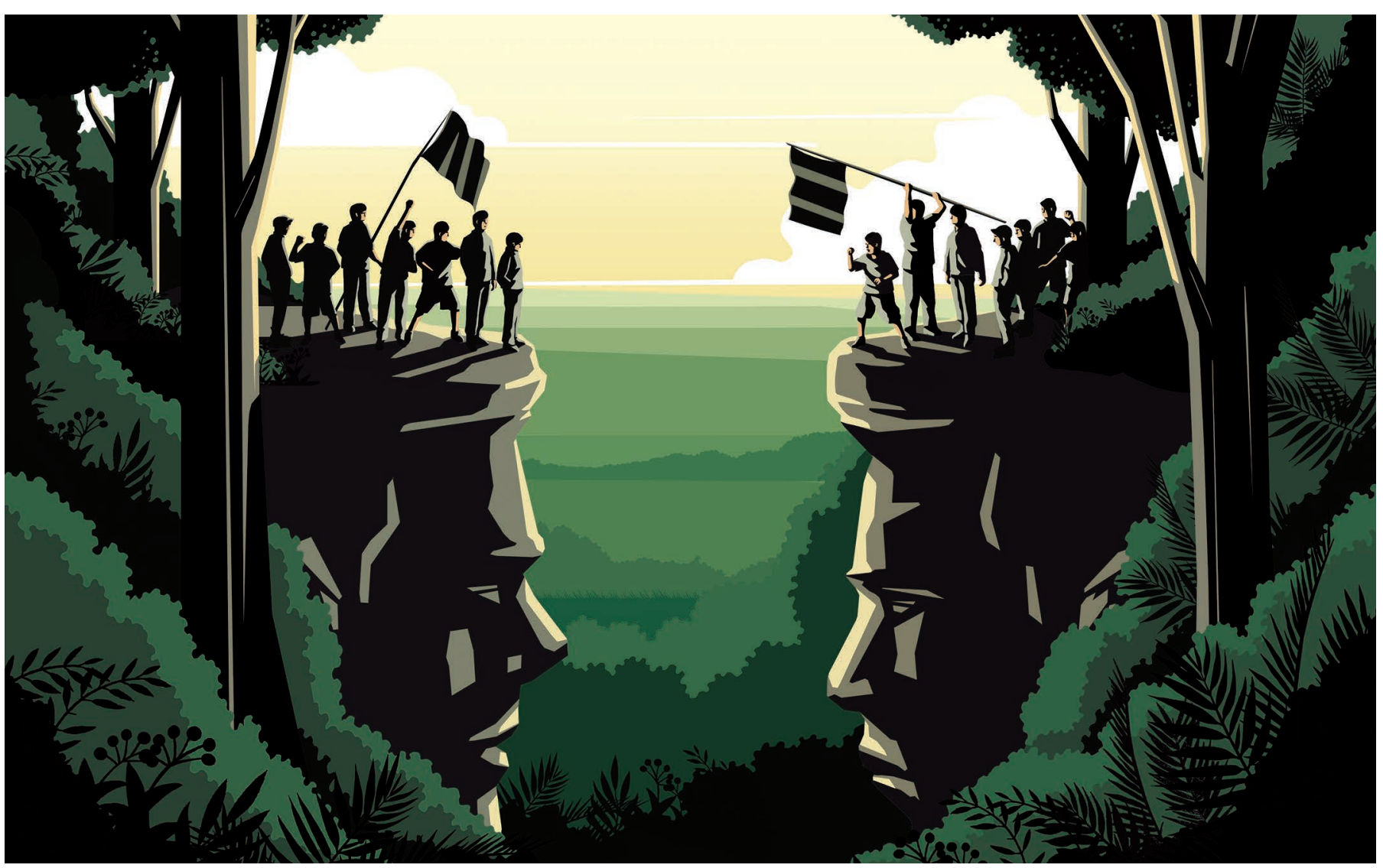

PSYCHOLOGY

\title{
War and peace and summer camp
}

\section{Alex Haslam appraises an account of key psychology experiments on conflict and cooperation.}

A few years after the Second World War, Muzafer Sherif conducted possibly the most complex field studies ever attempted in social psychology. Sited in summer camps around the United States, they focused on conflict and cooperation within and between two groups of about a dozen 11- and 12-year-old boys. The children were never informed that they were taking part in research. In each study, Sherif and his fellow researchers spent up to three weeks disguised as counsellors and caretakers, manipulating features of the camp set-up - in particular, the structure of team competitions and challenges - to examine their impact on group relations.

In The Lost Boys, Gina Perry puts these extraordinary experiments under the microscope. As in her 2013 book Behind the Shock Machine, which probed psychologist Stanley Milgram's 1960s research on obedience, she is unsatisfied with the halftruths lazily handed down in textbooks. Her aim is to make a distinctive contribution to the current debate about replication and reproducibility in social psychology. She goes in search of the stories behind the research, in particular reassessing Sherif's legacy through the recollections of study participants and research collaborators. The result is an enlightening read, and a ripping yarn.

All three studies featured a phase in which the two groups competed for scarce resources such as prized penknives. In other respects, their designs were quite different. In the 1949 and 1953 studies, the boys underwent a phase of making friends. They were then assigned to one of two distinct groups that cut across friendship lines.

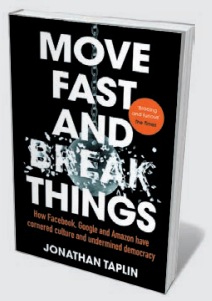

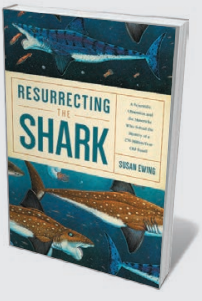

Resurrecting the Shark

Susan Ewing PEGASUS (2018)

Helicoprion, a bizarre prehistoric shark with teeth set in a spiral whorl, swam the oceans more than 270 million years ago. It remains shrouded in mystery. Susan Ewing traces how the fossil obsessed scientists for centuries, and how new research could resolve how its teeth fit into its jaw. 
In the 1954 study, at Robbers Cave State Park in Oklahoma, there was no initial friendship phase. Moreover, competition was followed by a period in which the two groups could achieve a prized outcome (such as watching a movie) only if they cooperated (say, by pooling group funds). The studies

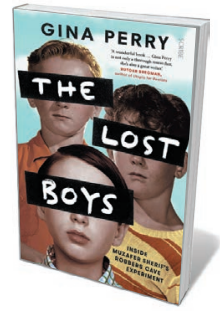

The Lost Boys: Inside Muzafer Sherif's Robbers Cave Experiments GINA PERRY Scribe (2018) were very much of their time: the scientists selected white, Protestant boys who were deemed psychologically 'well adjusted'.

As Sherif and his colleagues reported in later texts - notably the 1966 book Group Conflict and Co-operation - their manipulations profoundly affected the boys' behaviour. In particular, as predicted by 'realistic conflict' theory, competition generally led to 'us-them' group identities: well-mannered boys were turned into aggressive, prejudiced adversaries. Significantly, at Robbers Cave, this process was then reversed with the requirement to cooperate in the study's final phase.

Sherif's research is less well known than Milgram's, or later classic studies by Solomon Asch on conformity and Philip Zimbardo on tyrannical power dynamics (B. Maher Nature 523, 408-409; 2015). But what has made Sherif's legacy clearer and more enduring is the meticulous theoretical work that informed his studies' design. Sherif was no blind experimentalist. Rather, his ambitious goal was to create an empirical landscape capable of capturing the richness of 'big picture' social relations.

In many ways, this concern was a reflection of his own tumultuous life. As Perry clearly documents, that had been marked by external conflicts and inner torture. Before and after the Second World War, Sherif had moved back and forth between his native Turkey and the United States in the face of threats posed by nationalism, Nazism and McCarthyism. At various points, these pressures placed his work - sometimes his life - under threat, and led him to win and lose many friends along the way.

The Lost Boys illuminates Sherif's life and times, as well as Turkish history and how large field studies work. Sherif's own accounts of the latter give a sense that support for his theoretical hypotheses followed reasonably seamlessly from the studies' manipulations. In practice, it wasn't quite like that, as Perry's careful detective work reveals.

First, the boys responded in a range of ways to changing group relations and escalating conflict, and it is not always easy to weave these into a single account. Second, even when they were describing the same event, Sherif's co-investigators often interpreted it differently. Third, it was impossible for the investigators not to shape the boys' behaviour - not least because 'doing nothing' was itself laden with significance

\section{WELL-MANNERED BOYS WERE TURNED INTO AGGRESSIVE, PREJUDICED ADVERSARIES.}

(as when researchers refused to censure intergroup aggression, and the tacit approval led to escalation). Fourth, sometimes things simply didn't go to plan. This is seen most vividly in the 1953 study, which - to Sherif's dismay - had to be abandoned because the boys, realizing the tensions were engineered, refused to buy into group conflict.

Perry does a magnificent job of documenting these nuances. She tracks down participants, many now retired, and shares their reactions on first discovering that they had taken part in a famous study. Most were intrigued and hungry for information; some were conflicted. Perry rightly worries about the ethics of her own psychological archaeology.

Nevertheless, her efforts to fill in the inevitable gaps in her sources are not always convincing. Sometimes she does rather too much 'imagining' to join the dots between experimenters' actions and participants' reactions. This is especially problematic in the context of her rather unforgiving commentary on similar shortcomings in accounts by Sherif and his team. Although she questions whether Sherif's data collection was merely fleshing out a preconceived script, she herself is not immune to this charge.

A bigger problem is that Perry does not put the material she excavates to better use. Had she more thoroughly surveyed contemporary social psychological research on group conflict and collaboration, she would have found important clues that fit closely with the evidence she unearths, and pave the way for significant progress in the questions that Sherif posed.

For example, in his 1976 monograph Social Psychology and Intergroup Relations, Michael Billig observed that Sherif's key theoretical failing was not factoring in the experimenters as the studies' third group. Michael Platow and John Hunter have pointed out that Sherif himself recognized that the effects of group membership (such as in-group affinity) preceded competition, and so seem to be as dependent on internalized group identity as on the battle for scarce resources (in ways that Henri Tajfel and John Turner would later unpack in their social identity theory). More generally, Sherif failed to appreciate how the participants and researchers would follow his own lead (in particular, in his cultivation of shared identity). As research has since clarified, this is a blind spot in many classic social psychology studies - not least those of Milgram and Zimbardo.

In The Lost Boys, Perry opens the door to clearer theorizing about these crucial processes of identity and influence, but she fails to walk through it. In these terms, her book leaves the reader concerned not just for the boys' lost voices, but for Sherif's. He argued passionately and compellingly for theoretical progress in social psychology. Today, when a focus on empirical replicability often drowns out the equally important requirement for strong integrative theory, we need that voice as much as we did 70 years ago.

Alex Haslam is professor of psychology and Australian Laureate Fellow at the University of Queensland in Brisbane. His most recent book is The New Psychology of Health (with Catherine Haslam, Jolanda Jetten, Tegan Cruwys and Genvieve Dingle). e-mail:a.haslam@uq.edu.au

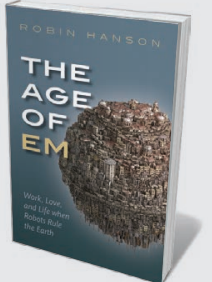

The Age of Em: Work, Love, and Life when Robots Rule the Earth Robin Hanson OXFORD UNIV. PRESS (2018) Marshalling economics, physics and philosophy, Robin Hanson predicts a future run by brain emulations ("ems"), featuring era-specific issues such as "mind theft". Hanson's predictions detail a world both uncanny and eerily familiar.

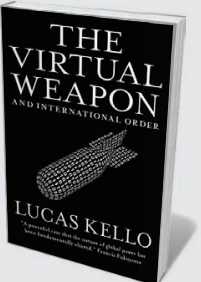

The Virtual Weapon and International Order Lucas Kello YALE UNIV. PRESS (2018) The cyber revolution clearly constitutes an ever-growing challenge to international order. Lucas Kello reflects on technology's role in political revolution, and the importance of aligning international-relations studies with the unruly expansion of cyberspace. 